\title{
The Reform Research on Practical Teaching System of Hydrology and Water Resources Engineering Based on CDIO
}

\author{
Qiaohuan Wang* \\ School of Water Resources and Environmental Engineering \\ East China University of Technology \\ Nanchang, Jiangxi, 330013, China \\ 53262205@qq.com \\ Dongliang Wang \\ School of Water Resources and Environmental Engineering \\ East China University of Technology \\ Nanchang, Jiangxi, 330013, China \\ dlwang@ecit.cn
}

\author{
Chunfeng He \\ School of Civil \& Architecture Engineering \\ East China University of Technology \\ Nanchang, Jiangxi, 330013, China \\ cfhe@ecit.cn
}

\author{
Chaoming Li \\ School of Water Resources and Environmental Engineering \\ East China University of Technology \\ Nanchang, Jiangxi, 330013, China \\ cmli@ecit.cn
}

\begin{abstract}
Practical teaching plays a very important role in training the applied talents of hydrology and water resources engineering (or called hydrological major) in East China University of Technology. Facing the current problems of the traditional practical teaching system, the main problems are analyzed in this paper. In order to solve the problems and meet the needs of social development for applied talents, the international concept of CDIO (Conceive, Design, Implement and Operate) is introduced and applied in practical teaching. The reform of practical teaching methods, contents, universityenterprise cooperation and evaluation mechanisms are made. Meanwhile, the competitive projects of scientific and technological innovation are increased in the practical teaching. It is showed that it can improve the students' engineering practice ability, team-cooperation ability, and comprehensive innovation ability, and also help teachers to enhance practical teaching level. Thus, this new practical teaching system is very effective and feasible, and will also give some useful experience to other similar majors.
\end{abstract}

Keywords-practical teaching; CDIO; engineering practical ability; team-cooperation

\section{INTRODUCTION}

With the development of society, more and more higher comprehensive applied talents are demanded. The reform of talent training model in higher education is becoming inevitable, especially of practical teaching system which is very important in training the students engineering practice ability, team-cooperation ability, etc. With the features of nuclear hydrogeology, the hydrology and water resources engineering (or called hydrological major) in East China University of Technology is one of the strongest practical engineering majors. But in a long time, it doesn't completely change the subordinate position of practical teaching in traditional subject education mode ${ }^{[1]}$. Thus, there are some problems in the practical teaching. For example, single teaching method, inappropriate teaching contents, imperfect evaluation mechanisms and lacking of high-skilled teachers. As a result, it is difficult for students to find a suitable job and to adapt to the new job immediately. In order to catch up with the society and improve the quality of practical teaching, it is high time to reform the traditional practice teaching.

Based on traditional practical teaching, the reform research object is explored in this article. The international engineering education model - CDIO is introduced and its concept is very suitable for the engineering majors. Adopting the CDIO, the new practice system which emphasizes on improving the engineering practice ability is set up. This article aims at giving some useful experience for other similar majors.

\section{THE MODEL OF CDIO ENGINEERING EDUCATION}

CDIO is a kind of advanced teaching model which is formally launched by Massachusetts Institute of Technology and other three famous universities initially in $2000^{[2]}$. It includes conceiving, designing, implementing and operating for higher engineering education. Compared with traditional teaching, CDIO model emphasizes on practice and teamcooperation $^{[3]}$. Its ability syllabus contains four parts, as shown in Fig. $1^{[4]}$. Using the syllabus in practice teaching, it is very useful to cultivate students' ability of engineering practice and promote coordinated development of students and society. It can encourage students' enthusiasm and initiative, and highlight student-centered status in practical teaching ${ }^{[4]}$. So it plays a decisive role in realizing the internationalization of engineering education. 


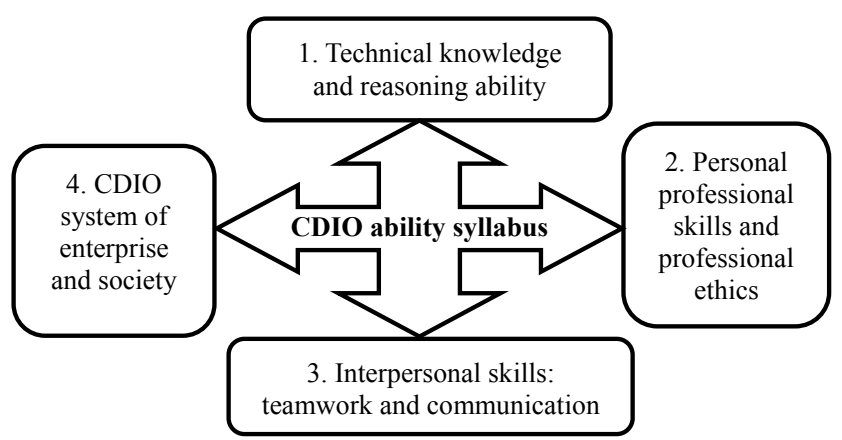

Fig. 1. The CDIO ability syllabus

CDIO model is used in Shantou University, Tsing- Hua University. It plays an important role for these universities to improve these students' ability of practice. The outstanding results have verified the CDIO model is scientific and feasible. CDIO model which has been developing rapidly in other universities sets off a wave of reform in higher engineering education.

\section{Problems In the Traditional Practical Teaching SYSTEM}

Based on analysis the situation of hydrology and water resources engineering in East China University of Technology, students face many serious problems, such as employment pressure, adaption to the practical work and so on. Obviously, the reason is that the traditional practical teaching system doesn't adapt to the development of society. There are several aspects as follows.

\section{A. The Single Method of Teaching in Traditional Practical Teaching}

For the teaching of practical, tradition teaching model is LBL (Lecture-Based Learning) ${ }^{[2]}$. This model completely ignores students' learning initiative and creativity. In the experiment teaching, teachers explain the experimental process firstly, then students doing the experiments. Students just copy the experimental process and never think about how to do it or why to do it. In the practical teaching, teachers also use LBL model to explain every bases when they guide students to visit the practical bases. Because of this model, students play a passive role in learning and their ability of active thinking about the knowledge is limited. Consequently, they lose the interest of learning knowledge and the ability of self-learning.

\section{B. The Inappropriate of Contents in Traditional Practical Teaching}

With the development of society, practical teaching contents should keep up with the pace of The Times. But in practice, many of the practical teaching contents have little change. In experiment teaching, there are many verification and demonstration experiments, but lack of design, comprehensive and innovative experiments. In practical teaching, the internship bases are so old and some even disappeared, at the same time, the practical contents have poor operational. In the enterprise practical teaching, the enterprise cooperation projects are so few and practical contents become a mere formality. So in the whole practical teaching, it lacks engineering practical teaching contents, students can't improve their engineering practical ability.

\section{The Lacking of Highly Skilled Teachers in Traditional Practical Teaching}

Teachers of practical teaching who are not only like the people of imparting knowledge and skills, but also like the engineers and managers, play a very important role in training the ability of innovation and practice ${ }^{[5]}$. For the current situation, there are many teachers especially young teachers who have enough theoretical knowledge, but they lack the exercise in practice. In practical teaching, they always impart the theoretical knowledge as theory teaching. As a result, it is difficult to develop the practical skills of students. In the long run, the quality of practical teaching becomes worse and worse.

\section{The Imperfect of Evaluation Mechanism in Traditional Practical Teaching}

The aim of practical teaching valuation is to find the deficiencies in practical teaching, and then teachers can improve and develop $\mathrm{it}^{[5]}$. But in traditional practical teaching, the only way to evaluate the results of practical teaching is the similar written reports. The most important thing of learning process and teaching process is ignored. It is difficult to cultivate the students' ability of innovation, practical and cooperation and so on. At the same, teachers also can't improve their practical teaching level.

\section{Reform of Practical Teaching System Based on CDIO}

After analyzing the above problems, it is necessary to conduct self-criticism and self-reflection, and then to find the reasons. According to the research, the basic reason is the traditional education concept which hasn't already adapt to the development of society. In order to solve these problems, according to the successful cases of practical teaching and the training aim of hydrological major, the CDIO engineering education concept to reform our traditional practical teaching system is explored.

\section{A. Transformation Practical Teaching Methods}

The concept of CDIO advocates students joining into the real-condition to inspire their learning mind. According to the interest and learning ability of students, different teaching methods is chosen to encourage students to learn positively, such as problem-based teaching method, project-type teaching method, situational teaching method, and so on. These teaching methods change the teachers' predominance into students' predominance. Students can solve the practical problems either by themselves or teams. They can learn knowledge from practice. It is very useful to improve students' positivity learning ability, team-cooperation and communication ability.

\section{B. Optimization the Practical Teaching Contents}

According to the characteristics and training objectives of hydrological major, the practical teaching contents should be integrated and optimized. The practice teaching contains the courses experiments and the practice. For the courses experiments, the design, comprehensive and innovative experiments can train the engineering practice ability of students in the universities. So many different design 
experiments, comprehensive and innovative experiments should be riched in each experiment courses. Such as in the course of fundamentals of hydrogeology, the three comprehensive experiments are increased, at the same time, some courses (radioactive hydrogeology, uranium hydrogeochemical, and nuclear waste disposal, etc.) are opened new experiments contents. These experiment projects, which are fit for the development of hydrological major and come from engineering practice, include required experiments and optional experiments. According to personal interest and ability, students can choose different experiments to do. For the practice, it contains cognition practice, comprehensive skills training, and graduation practice. In order to satisfy the practice teaching, the old practical teaching bases must be improved, such as hot spring bases in Fuzhou, Jiangshan bases in Zhejiang, Meiling bases in Nanchang, and so on. And new practical teaching bases should be built, Such as Sanxia base. Each practical teaching base should have different contents. Students can know different hydrological and hydrogeology phenomenon and existing problems from the practice bases. They are able to understand what to do, how to do, what problems to face and to solve about their major.

These practical teaching contents can stimulate students learning interest and enthusiasm, and also cultivate the creative thinking ability of students. This will lay the foundation for the students in the future work and research.

\section{Establishment the Cooperativeness Relationship between Universities and Enterprises}

The cooperation between universities and enterprises or the enterprises participate is the critical path to come true the CDIO engineering education model ${ }^{[6]}$. In this cooperation process, it can realize the practical and scientific research, the combination of engineering practical and social application. According to the nuclear characteristics of hydrological major, two long-term cooperative relationship enterprises are built which is No.267 Exploration Team Geological Bureau of Jiangxi Nuclear Industry and Xinjiang Tianshan Uranium Co., Ltd. CNNC. Different enterprise engineers are invited to instruct teachers and students of hydrological major twice a year. At the same time, the teachers and students can also take part in engineering production process to improve their engineering practical ability.

\section{Perfect the Evaluation Mechanism of Practical Teaching}

Based on the CDIO, the practical teaching evaluation should run though the whole practical teaching process. It contains the evaluation of teachers' teaching process and students' learning process. According to different status of teaching, considering the personal-basic skills, interpersonal skills, practice-operated skills, and so on, the students' evaluation mechanisms of course learning, experiment learning, practice learning, enterprise learning and teachers' work evaluation mechanism are set $u^{[7]}$, as shown in Fig. 2. With the establishing of these evaluation mechanisms, it is effective in improving the quality of practical teaching and cultivating the high-level engineering talents.

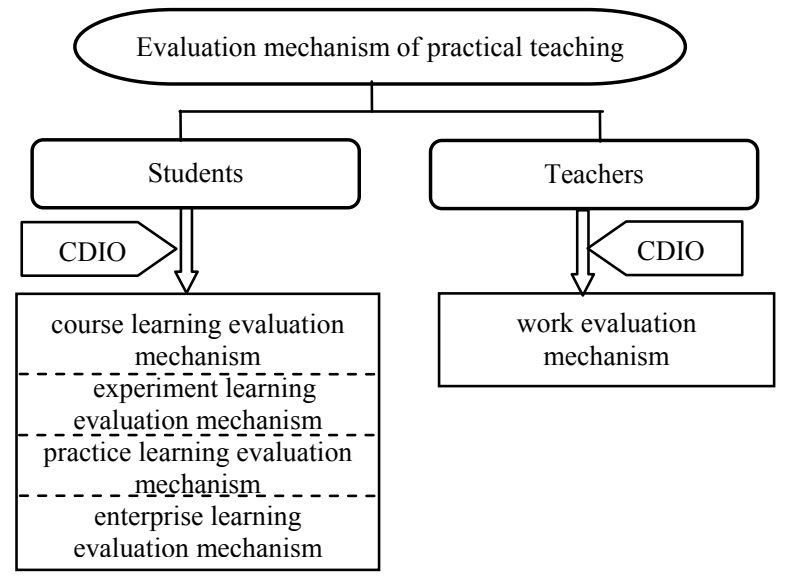

Fig. 2. The evaluation mechanism based on CDIO

\section{E. Increasing the Competitive Projects of Scientific and Technological Innovation in Practice}

In order to realize the learning by doing, it is very useful for students to participate in competitive projects of scientific and technological innovation. These projects which include national-level, provincial-level and school-level can supplement the practical teaching effectively. These competitive projects not only will help students to know a lot of knowledge and inspire their creative thinking, but also will increase team-cooperation sense and interpersonal communication chance with different universities. As a result, through the whole competitive process, students can master the conception, designing, implementation and operation process of projects. It is greatly effective in improving students' ability of analysis and solves the engineering problems, and management skills of engineering projects ${ }^{[8]}$.

\section{CONCLUSIONS}

Hydrological major has strong practical features in East China University of Technology. Facing the difficulty of employment in recent years, the existing problems are analyzed and the successful cases from domestic and overseas are studied. The CDIO engineering education model is very suitable for transform the traditional practical teaching system. Thus, the new practical teaching system based on CDIO is set up, and reform from practical teaching methods, contents, university-enterprise cooperation and evaluation mechanisms are made. Meanwhile, the competitive projects of scientific and technological innovation are increased in the practical teaching, as shown in Fig. 3. It is showed that the new practical teaching system strengthens the student-centered status. Using this new system, it can mobilize the initiative and interest of students and teachers. Ultimately, it is able to improve the students' engineering practical ability, team-cooperation ability, and comprehensive innovation ability, and also enhance the teachers' level of practical teaching and ability of keeping the practical teaching well in hand. The author thinks that the new system would have great significance of consult for other engineering majors. But everyone knows 'there is no best, only better', so it also needs to constantly enhance with the development of society in practice. 


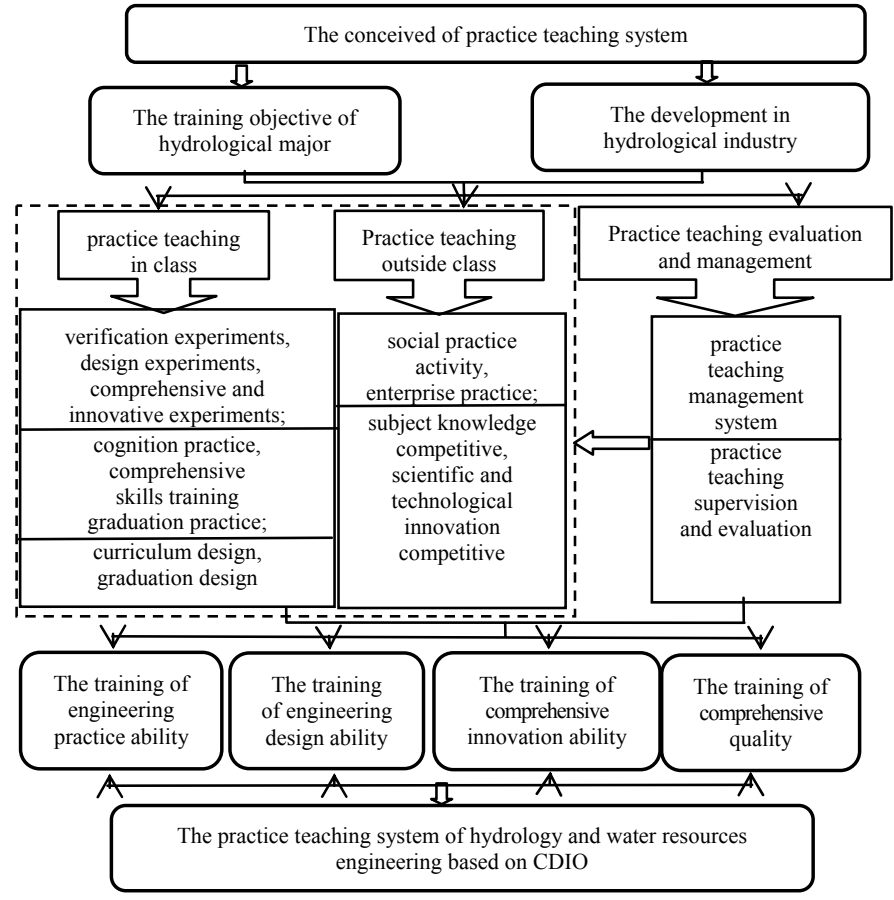

Fig. 3. The practice teaching system of hydrology and water resources engineering based on CDIO

\section{ACKNOWLEDGMENT}

This work was financially supported by Reform Research Subject of Higher Education in Jiangxi Province of
China, (Grant NO: JXJG-14-6-8, JXJG-15-6-11, JXJG-16-620).

\section{REFERENCES}

[1] S. E. Zhao, et al, "Research and Exploration of Engineering Practical Teaching Model Based on CDIO Teaching Concept," Journal of Chong Qing Jiao Tong University (Social Sciences Edition), vol. 12 (5), pp. 120-122,130, 2012. (In Chinese)

[2] Y.B.Wang, "Reform and Exploration on Electric Circuit Course Teaching Based on CDIO," Creative Education, vol.7 (3), pp. 478-481, 2016.

[3] P. H. Gu, et al, "The Development of Design Directed Engineering Curriculum Based on the CDIO Framework," World Transactions on Engineering and Technology Education, vol. 5 (2), pp. 267-270, 2006.

[4] G. H. Lin and Y. Q. Tang, "Application of CDIO in Practice and Training of an Engineering Automation Specialty," World Transactions on Engineering and Technology Education, vol. 13 (3), pp. 407-411, 2015.

[5] X. Q. Wu, et al, "The Research of Engineering Teaching Model Based on the Concept of CDIO," Animal Husbandry and Veterinary Medicine in Hei Longjiang, No. (12), pp. 256-258, 2016. (In Chinese)

[6] J. J. Li and Y. Q. Zhang, "Construction and Exploration of Chemical Engineering Practice System Teaching Based on the Concept of CDIO Education," Research in Teaching, vol. 39 (6), pp. 97-100, 2016. (In Chinese)

[7] Z. F. Liao, et al, "Software Engineering CDIO Practical Teaching System Frame," Computer Education, No. (11), pp. 128-131, 2010. (In Chinese)

[8] L. H. Qin, K. Shi and Z. B. Gan, "CDIO-based Research and Practical of Course System for the Specialty of Internet Things," Research in Higher Education of Engineering, No. (5), pp. 168-172, 2013. (In Chinese) 